\title{
Adenocarcinoma with mixed subtypes is a rare but aggressive histologic subtype in colorectal cancer
}

\author{
Hui Sheng ${ }^{1 \dagger}$, Xiaoli Wei ${ }^{2+}$, Minjie Mao ${ }^{3 \dagger}$, Jincan He${ }^{4}$, Tianqi $\mathrm{Luo}^{5}$, Shilin $\mathrm{Lu}^{4}$, Liye Zhou ${ }^{6}$, Zhixin Huang ${ }^{7^{*}}$ and \\ Anli Yang ${ }^{8^{*}}$ (D)
}

\begin{abstract}
Background: Although numerous studies have investigated the clinicopathologic and prognostic relevance of mucinous adenocarcinoma (MAC) and signet-ring cell carcinoma (SRCC) compared with classic adenocarcinoma (CA), little is known about the prognosis of adenocarcinoma with mixed subtypes (AM) and the differences among these four subtypes.

Methods: The statistics of colorectal cancer registered in the Surveillance, Epidemiology and End Results (SEER) database were retrieved and analyzed. We also compared the clinicopathologic and prognostic relevance between CA, SRCC, MAC, and AM.

Results: The frequencies of these four subtypes were 69.9\% (CA, $n=15,812$ ), 25.1\% (MAC, $n=5689$ ), 3.6\% (SRCC, $n=814$ ) and $1.4 \%(A M, n=321)$, respectively. All of MAC, SRCC, and AM were significantly related with aggressive features. Only SRCC and AM were identified as independent poor prognostic markers for overall survival by multivariate analysis. The aggressiveness of AM was between MAC and SRCC according to the clinicopathologic associations. The prognosis of AM was significantly worse than MAC but comparable with SRCC.

Conclusions: We confirmed the clinicopathologic relevance with aggressive features of MAC and SRCC, as well as poor prognostic relevance of SRCC by analyzing a large study population data set. Furthermore, we identified $\mathrm{AM}$ as a rare but aggressive histologic subtype in colorectal cancer, to which particular attention should be given in clinical practice.
\end{abstract}

Keywords: Colorectal cancer, Histologic subtypes, Prognosis

\section{Background}

Colorectal cancer (CRC) is the third most common malignancy in the US and the fifth in China [1,2]. Earlystage CRC is curable by radical surgery. However, cancer recurrence and distant metastasis occur frequently after curative treatment, especially for more advanced stage

\footnotetext{
*Correspondence: huang199695@126.com; yangal@sysucc.org.cn

${ }^{\dagger} H u i$ Sheng, Xiaoli Wei and Minjie Mao contributed equally to this work. ${ }^{7}$ Department of Emergency, Foshan Traditional Chinese Medicine

Chancheng High-tech Zone Hospital, 10 Chunyang Road, Foshan 52800, Guangdong Province, China

${ }^{8}$ Department of Breast Oncology, Sun Yat-sen University Cancer Center, State Key Laboratory of Oncology in South China, Collaborative Innovation Center for Cancer Medicine, 651 Dong Feng Road East, Guangzhou 510060, Guangdong Province, China

Full list of author information is available at the end of the article
}

CRC patients, which leads to poor outcomes [3-8]. Thus, the identification of prognostic markers is of great importance in patient management and decision making.

American Joint Committee on Cancer / Tumor-nodemetastasis (AJCC/TNM) staging system is well accepted as the most efficient prognostic factor in CRC [9] However, heterogeneity of prognosis exists even among patients at the same TNM stage. Thus, it underlines the importance of incorporating multiple prognostic markers, such as tumor differentiation degree [10-13], some genetic markers $[14,15]$, and several postoperative pathologic features [16-18].

(c) The Author(s). 2019 Open Access This article is distributed under the terms of the Creative Commons Attribution 4.0 International License (http://creativecommons.org/licenses/by/4.0/), which permits unrestricted use, distribution, and reproduction in any medium, provided you give appropriate credit to the original author(s) and the source, provide a link to the Creative Commons license, and indicate if changes were made. The Creative Commons Public Domain Dedication waiver (http://creativecommons.org/publicdomain/zero/1.0/) applies to the data made available in this article, unless otherwise stated. 
The histologic subtypes of CRC have also been demonstrated with prognostic relevance. Most CRCs are adenocarcinomas, including three well-studied major subtypes: classical adenocarcinoma (CA), mucinous adenocarcinoma (MAC), and signet-ring cell carcinoma (SRCC) [19]. MAC was primarily identified as a negative prognostic factor [20]. However, subsequent studies have proved that the prognostic difference between SRCC and MAC is not independently significant [19, 21-23]. Furthermore, in stage II CRC, MAC is associated with high microsatellite instability (MSI-H) [24, 25], a marker of superior prognosis and no benefit from adjuvant 5-Fu chemotherapy. Thus in the 3rd version of 2012 National Comprehensive Cancer Network (NCCN) guidelines for colorectal cancer, a poor differentiation with MSI-H was removed from the list of high-risk factors for stage II CRC. SRCC has been widely recognized as a marker of aggressive tumors with inferior prognosis [26, 27]. While there may still be other histologic subtypes with distinct clinicopathologic and prognosis relevance apart from CA that need special concern in clinical management.

We conducted this study with Surveillance, Epidemiology, and End Results Program (SEER) database for CRC registered during 2010-2012 to investigate the frequency distribution of histologic subtypes in CRC, and explore other possible histologic subtypes with distinct clinical significance compared with CA. Additionally, we sought to describe the impact of histological subtypes on prognosis.

\section{Methods}

\section{The SEER database and cases selection}

As the largest publicly available cancer dataset worldwide, the SEER database collects cancer information including morbidity, mortality, and disease status of patients with malignancies across the US. Unified and standardized tumor information in the database is updated regularly. Here we focused on colorectal adenocarcinomas, coded by the 3rd edition of the International Classification of Diseases for Oncology (ICD-O-3) as C18.0, C18.2 - C18.7, C19.9 and C20.9 for topography and 8140-8147, 8210-8211, 8220-8221, 8255, 8260$8263,8480-8481,8490$ and 8574 for histology. In addition, the present study only covered patients with records of histologic codes (ICD-O-3), the $7^{\text {th }} \mathrm{AJCC} /$ TNM classification and follow-up information. Patients with other tumors as primary tumor were excluded.

\section{Histologic subtypes}

The ICD-O-3 (updated in 2000) was used in tumor or cancer registries for coding the topography and histology. We summarized the histologic codes and the relevant corresponding descriptions in Additional file 1:
Table S1. A further categorization was conducted to categorize patients into four histologic subtypes, including CA (Code 8141-8147, 8210-8211, 8220-8221, 8260-8263), MAC (Code 8480-8481), SRCC (Code 8490), and AM (Code 8255). Adenocarcinoma with neuroendocrine differentiation (Code 8574) was not included in the final analysis because of the difficulty in categorization and limited sample size.

\section{Statistical analysis}

All the analyses were conducted with SPSS for Windows V.13.0. (SPSS Inc., Chicago, IL, USA). The frequency distribution of histologic subtypes was calculated with descriptive method. The comparisons of clinicopathologic characteristics between $\mathrm{CA}$ and the other histologic subtypes including MAC, SRCC, and AM were performed with chi-square test or Kruskal-Wallis $\mathrm{H}$ test. CRC-specific overall survival (OS) was the interval from the date of CRC diagnosis to the date of last follow-up or cause-specific death. Patients alive at the last followup or died of other causes were classified as censored cases. Univariate and multivariate analyses were performed for prognostic differences between histologic subtypes. Survival curves were plotted and compared using the Kaplan-Meier method and the log-rank test. A two-tailed $P$ value $<0.05$ was considered statistically significant. Variables with a $P$ value $<0.05$ in univariate analyses were included in multivariate analyses. We adopted "forward: conditional" method for multivariate analyses. With this method, only variables with a significant $P$ value would be included for the estimation of hazard ratio $(H R)$ 95\% confidence interval $(95 \% C I)$ in the Cox proportional hazards model.

\section{Results}

The frequency distribution of histologic subtypes in CRC 71,810 CRC patients were included in this study from SEER registers during 2010-2012. According to the ICD-O-3 codes and description, 49,131 (68.4\%) cases were classified as adenocarcinoma NOS, not otherwise specified. The rest 22,679 (31.6\%) patients were analyzed for the frequency distribution of histologic subtypes in CRC (Additional file 1: Table S1). Except for adenocarcinoma with neuroendocrine differentiation (Code 8574), which is a distinct subtype but accounts for a very small population, all the others $(n=22,636,99.8 \%)$ were included and categorized into four histologic subtypes: CA, MAC, SRCC, and AM. The most common subtype was CA, with 15,812 cases accounting for $69.9 \%$. The numbers and frequencies of MAC, SRCC, and AM were $5689(25.1 \%), 814(3.6 \%)$, and $321(1.4 \%)$, respectively (Table 1). Both SRCC and AM are relatively rare with their frequencies lower than $5 \%$. 
Table 1 The frequency distribution of classical adenocarcinoma, mucinous adenocarcinoma, signet-ring cell carcinoma and adenocarcinoma with mixed subtypes in colorectal cancer

\begin{tabular}{ll}
\hline Histologic subtype & Number (\%) \\
\hline Classical adenocarcinoma & $15,812(69.9)$ \\
Mucinous adenocarcinoma & $5689(25.1)$ \\
Signet-ring cell carcinoma & $814(3.6)$ \\
Adenocarcinoma with mixed subtypes & $321(1.4)$ \\
\hline
\end{tabular}

\section{Comparisons of clinicopathologic differences between histologic subtypes}

MAC was more common in female $(P<0.001)$ and older patients $(P<0.001)$ compared with $C A$. There was no significant difference in the distribution of gender and sex between CA and SRCC or AM. Compared with $\mathrm{CA}$, all the other three subtypes were found less common in rectal cancer (all $P<0.001$ ). In addition, MAC, SRCC, and AM, were significantly associated with some features of aggressiveness, including poor tumor differentiation, large size of primary tumors, high level of carcinoembryonic antigen (CEA), advanced $\mathrm{T}$ stage and $\mathrm{N}$ stage, distant metastasis, high positive rates of circumferential resection margin (CRM) involvement, and perineural invasion, as well as frequent presence of tumor deposits (all $P<0.001$, Table 2, $P 1$ using "CA" as the reference).

We further compared the clinicopathologic differences between AM and the other two relatively more aggressive histologic subtypes: MAC and SRCC. Compared with MAC, AM was found more frequently in males $(P=0.05)$. AM was also associated with aggressive tumor characteristics including poor differentiation $(P<0.001)$, more advanced $\mathrm{T}$ and $\mathrm{N}$ stage $(P<0.001)$, distant metastasis $(P=0.002)$, higher positive rates of CRM $(P<0.001)$, perineural invasion $(P<0.001)$, and frequent presence of tumor deposits $(P<0.001)$. As for the comparison between AM and SRCC, AM was associated with better differentiation $(P<0.001)$, distant metastasis $(P<0.001)$, and perineural invasion $(P=0.003)$. No differences were found in other clinicopathologic characteristics between AM and SRCC. Detailed information was shown in Table 2 ( $P 2$, using "MA" as the reference).

\section{The prognostic value of histologic subtypes for CRC specific OS}

We compared the 3-year CRC specific OS rates between histologic subtypes (Table 3) in the general population and subgroups stratified by TNM stage $(0+\mathrm{I} / \mathrm{II} / \mathrm{III} / \mathrm{IV})$, tumor location (Colon / Rectum), sex (Male / Female) and age $(\leq 66 />66)$. The 3-year OS rates was $90.3 \pm 0.004 \%, 71.6 \pm 0.01 \%, 38.0 \pm 0.06 \%$ and $49.8 \pm 0.06 \%$ for CA, MAC, SRCC, and AM, respectively. MAC, SRCC, and AM showed significantly poor survival rates compared with CA. And this difference sustained in most of the subgroups, except for certain TNM stage subgroups. For instance, in stage IV patients, MAC did not show a significant difference in the 3-year OS rate compared with CA. Additionally, there was no obvious difference in the 3-year OS rate when comparing SRCC and CA in stage $0+\mathrm{I}$ patients. So was when comparing AM and CA in stage II patients. Compared with AM, MAC showed significantly better 3-year OS in the general population as well as in most subgroups, while no prognostic differences were found between AM and SRCC (Table 3, P1 using "CA" as the reference, $P 2$ using "MA" as the reference). The CRC-specific OS of the four subtypes estimated using the Kaplan-Meier method were shown in Fig. 1. When stratified by TNM stage, AM remained presenting significantly worse CRC-specific OS compared with CA in stage $0+\mathrm{I}$, stage III, and stage IV groups (Additional file 2: Figure S1, $P=0.04$, $P<0.001, P=0,001$ ), but not in stage II (Additional file 2: Figure $\mathrm{S} 1, P=0.43$ ).

We then conducted univariate and multivariate analysis to test the prognostic differences in CRC specific OS between histologic subtypes. By univariate analysis, besides histologic subtypes $(P<0.001)$, other significant prognostic factors including age $(\leq 66 />66, P<0.001)$, tumor location (Colon / Rectum, $P<0.001$ ), grade (Well differentiated / Moderately differentiated / Poorly differentiated or undifferentiated, $P<0.001)$, TNM stage $(0+$ I/II/III/IV,$P<0.001$ ), race (American Indian/Alaska Native / Asian or Pacific Islander / Black / White, $P<$ 0.001), insurance status (Insured / Others, $P<0.001$ ), marital status (Married / Widowed / Others, $P<0.001$ ), CEA level (Normal / Borderline / Elevated, $P<0.001$ ), CRM (Negative / Positive, $P<0.001$ ), perineural invasion (Negative / Positive, $P<0.001$ ) and tumor deposits (Absent / Present, $P<0.001$ ) were identified. All the significant prognostic factors identified by univariate analysis were included for multivariate Cox regression analysis. Factors remained as independent prognostic factors included age $(P<0.001)$, grade $(P=$ $0.001)$, TNM stage $(P<0.001)$, marital status $(0.003)$, CEA $(P<0.001)$, CRM $(P<0.001)$, tumor deposits $(P<0.001)$, and histologic subtype $(P<0.001)$. After adjusting for confounding factors, MAC didn't have a significantly different prognosis $(P=0.20$, hazard ratio $(H R)$ and 95\% confidence interval (95\% CI): 1.14 (0.931.39)), while the inferior prognosis of SRCC and AM remained significant $(P<0.001$ and $P=0.003, H R$ and 95\% CI: 1.88 (1.37-2.58) and 1.89 (1.25-2.85), respectively) compared with CA (Table 4). In addition, compared with AM, MAC had a significantly better prognosis $(P=0.01, H R$ and 95\% CI: 0.60 (0.40-0.90)), while no survival difference was found between AM and 


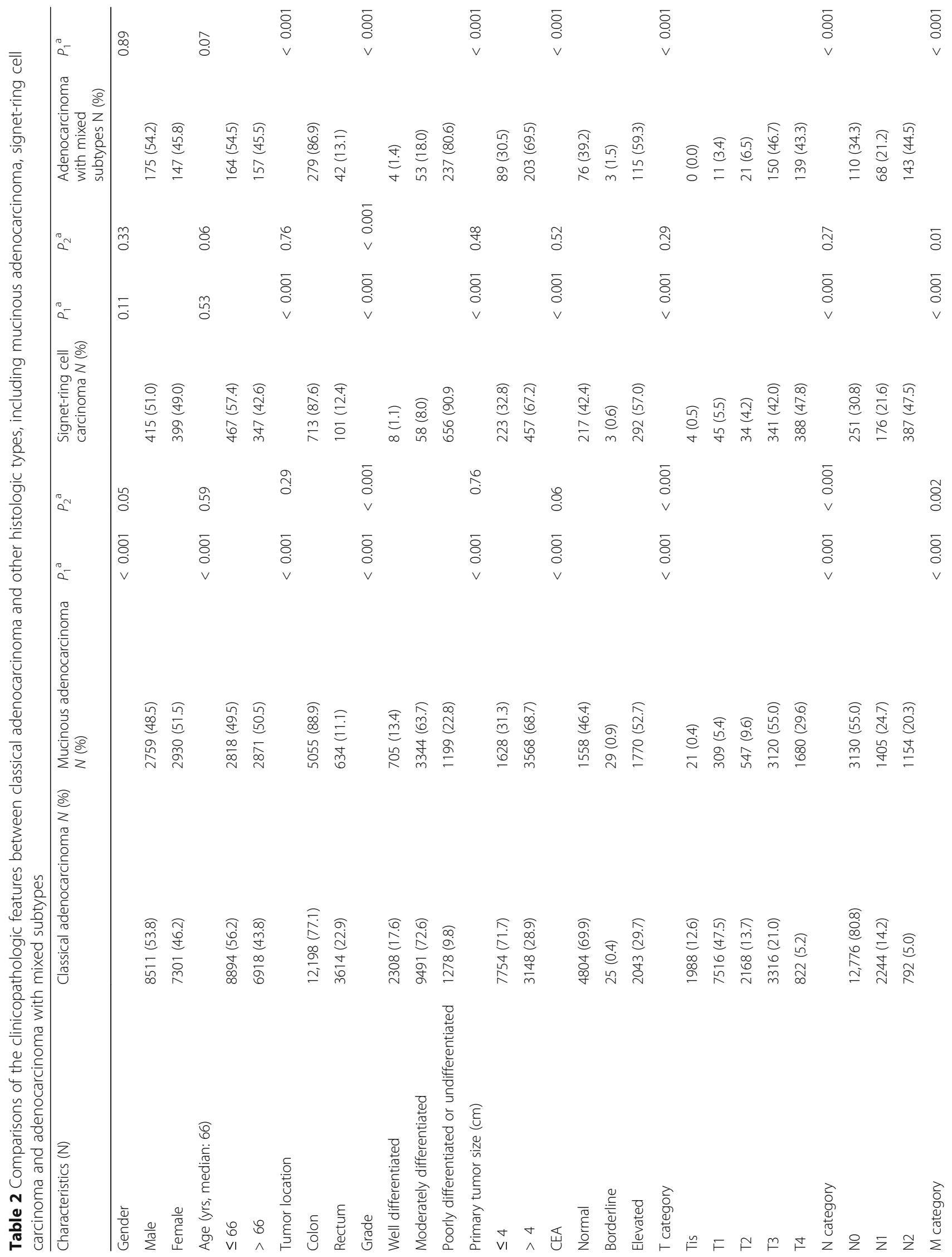




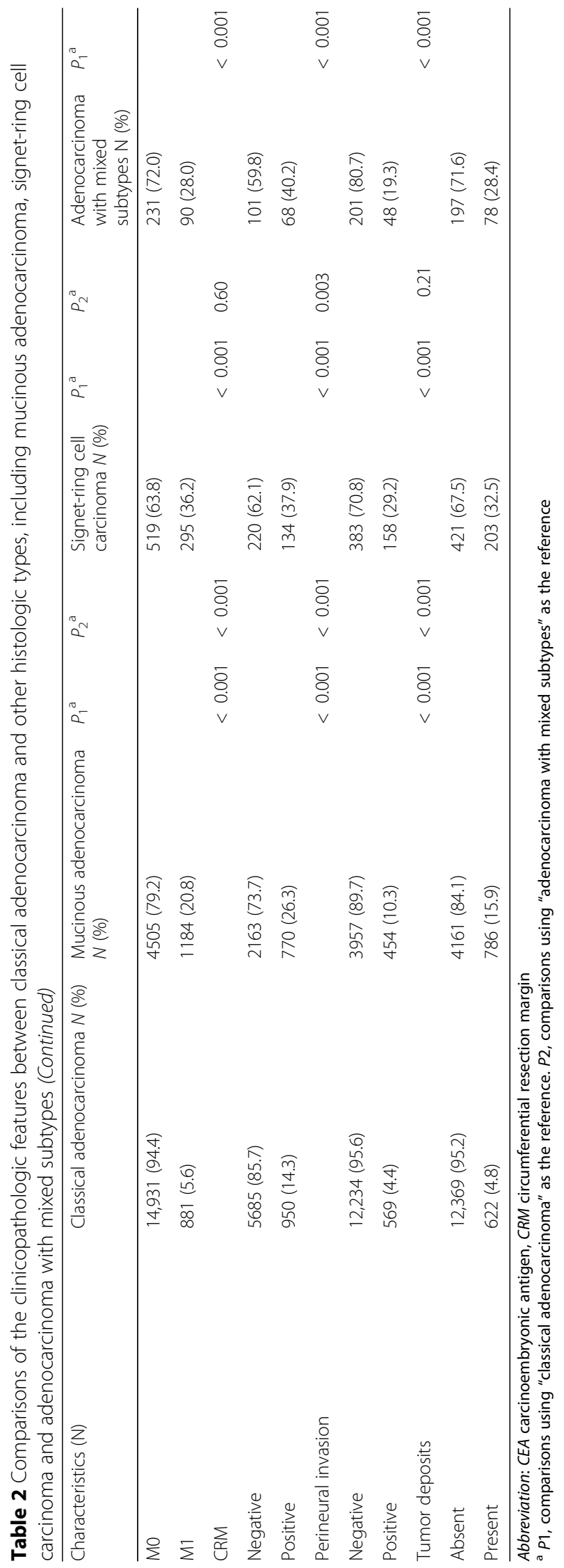




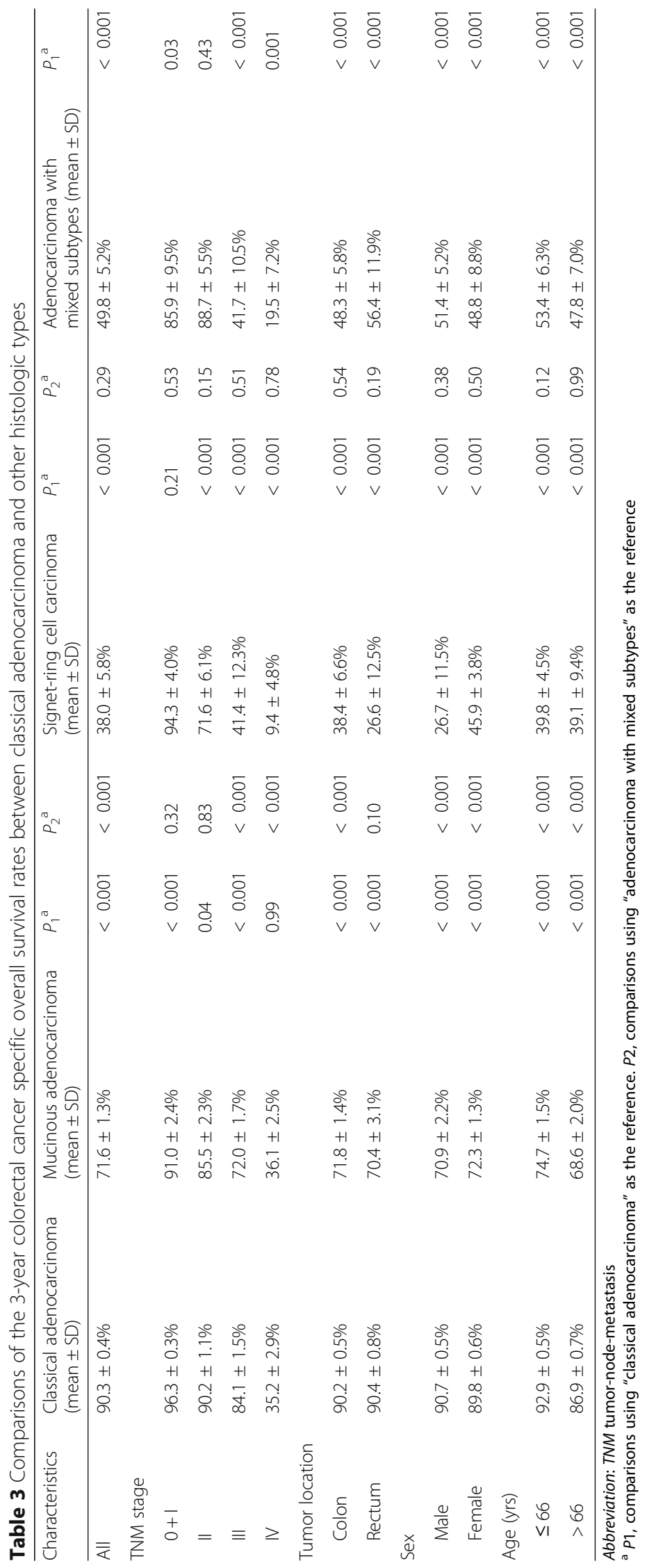




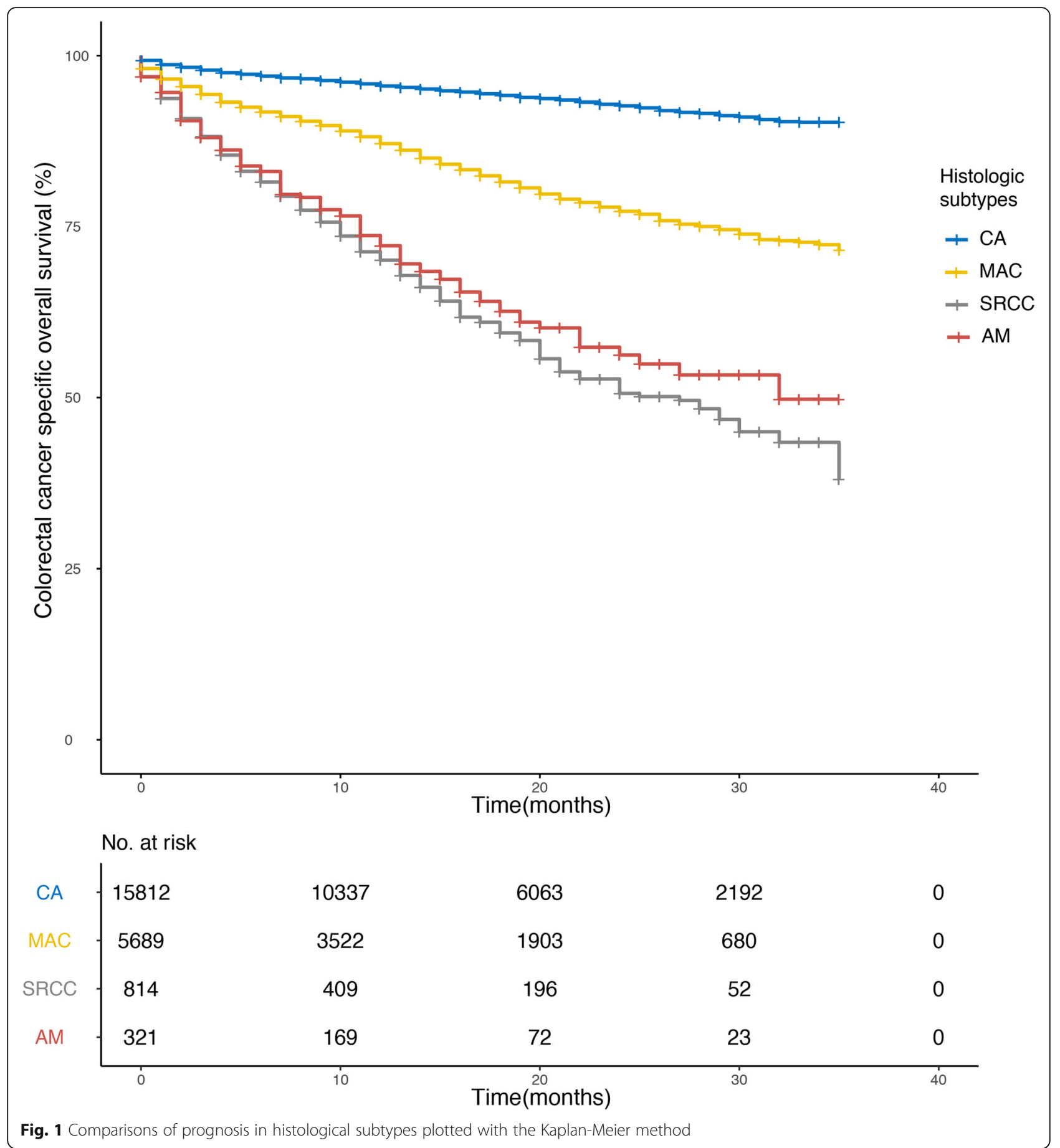

SRCC $(P=0.98, \quad H R$ and 95\% $C I: 0.99 \quad(0.65-1.53))$ (Table 4).

\section{Discussion}

In this study, we compared the clinicopathologic and survival differences of CA with two previously widely investigated histologic subtypes, MAC and SRCC. Both subtypes were significantly associated with more aggressive features compared with CA, while only SRCC showed significantly poorer survival. Furthermore, we also focused on another rare histologic subtype, AM, whose frequency is about $2 / 5$ of SRCC. We identified $\mathrm{AM}$ as a subgroup significantly associated with more advanced tumor grade and stage, as well as worse survival compared with CA. In addition, the aggressiveness of AM was between MAC and SRCC according to the clinicopathologic associations. The prognosis of AM was found comparable with SRCC and worse than MAC. 
Table 4 Univariate and multivariate analysis for the colorectal-specific overall survival of histologic subtypes in colorectal cancer

\begin{tabular}{|c|c|c|c|c|}
\hline \multirow[t]{2}{*}{ Characteristics } & \multirow{2}{*}{$\begin{array}{l}\text { Univariate analysis } \\
P \text { value }\end{array}$} & \multicolumn{3}{|l|}{ Multivariate analysis } \\
\hline & & $H R$ & $95 \% \mathrm{Cl}$ & $P$ value \\
\hline Sex & 0.06 & & & \\
\hline \multicolumn{5}{|l|}{ Male } \\
\hline \multicolumn{5}{|l|}{ Female } \\
\hline Age (yrs) & $<0.001$ & 2.26 & $1.87-2.73$ & $<0.001$ \\
\hline \multicolumn{5}{|l|}{$\leq 66$} \\
\hline \multicolumn{5}{|l|}{$>66$} \\
\hline Tumor location & $<0.001$ & & & \\
\hline \multicolumn{5}{|l|}{ Colon } \\
\hline \multicolumn{5}{|l|}{ Rectum } \\
\hline Grade & $<0.001$ & & & 0.001 \\
\hline Well differentiated & & 1 & Reference & \\
\hline Moderately differentiated & & 1.50 & $0.96-2.34$ & 0.08 \\
\hline Poorly differentiated or undifferentiated & & 2.06 & $1.30-3.28$ & 0.002 \\
\hline TNM stage & $<0.001$ & & & $<0.001$ \\
\hline $0+1$ & & 1 & Reference & \\
\hline$\|$ & & 2.04 & $1.24-3.35$ & 0.01 \\
\hline III & & 5.12 & $3.23-8.09$ & $<0.001$ \\
\hline IV & & 15.39 & $9.55-24.79$ & $<0.001$ \\
\hline Race & $<0.001$ & & & \\
\hline \multicolumn{5}{|l|}{ American Indian/Alaska Native } \\
\hline \multicolumn{5}{|l|}{ Asian or Pacific Islander } \\
\hline \multicolumn{5}{|l|}{ Black } \\
\hline \multicolumn{5}{|l|}{ White } \\
\hline Insurance status & $<0.001$ & & & \\
\hline \multicolumn{5}{|l|}{ Insured } \\
\hline \multicolumn{5}{|l|}{ Others } \\
\hline Marital status & $<0.001$ & & & 0.003 \\
\hline Married & & 1 & Reference & \\
\hline Widowed & & 1.40 & $1.10-1.78$ & 0.01 \\
\hline Others & & 1.33 & $1.08-1.63$ & 0.01 \\
\hline CEA & $<0.001$ & & & $<0.001$ \\
\hline Normal & & 1 & Reference & \\
\hline Borderline & & 1.43 & $0.45-4.51$ & 0.54 \\
\hline Elevated & & 1.76 & $1.44-2.15$ & $<0.001$ \\
\hline CRM & $<0.001$ & 1.47 & $1.22-1.77$ & $<0.001$ \\
\hline \multicolumn{5}{|l|}{ Negative } \\
\hline \multicolumn{5}{|l|}{ Positive } \\
\hline Perineural invasion & $<0.001$ & & & \\
\hline \multicolumn{5}{|l|}{ Negative } \\
\hline \multicolumn{5}{|l|}{ Positive } \\
\hline Tumor deposits & $<0.001$ & 1.70 & $1.39-2.08$ & $<0.001$ \\
\hline \multicolumn{5}{|l|}{ Absent } \\
\hline Present & & & & \\
\hline
\end{tabular}


Table 4 Univariate and multivariate analysis for the colorectal-specific overall survival of histologic subtypes in colorectal cancer (Continued)

\begin{tabular}{|c|c|c|c|c|}
\hline \multirow[t]{2}{*}{ Characteristics } & \multirow{2}{*}{$\begin{array}{l}\text { Univariate analysis } \\
P \text { value }\end{array}$} & \multicolumn{3}{|l|}{ Multivariate analysis } \\
\hline & & $H R$ & $95 \% \mathrm{Cl}$ & $P$ value \\
\hline Histologic subtype (classical adenocarcinoma as reference) & $<0.001$ & & & $<0.001$ \\
\hline Classical adenocarcinoma & & 1 & Reference & \\
\hline Mucinous adenocarcinoma & & 1.14 & $0.93-1.39$ & 0.20 \\
\hline Signet-ring cell carcinoma & & 1.88 & $1.37-2.58$ & $<0.001$ \\
\hline Adenocarcinoma with mixed subtypes & & 1.89 & $1.25-2.85$ & 0.003 \\
\hline Histologic subtype (adenocarcinoma with mixed subtypes as reference) & $<0.001$ & & & $<0.001$ \\
\hline Adenocarcinoma with mixed subtypes & & 1 & Reference & \\
\hline Classical adenocarcinoma & & 0.53 & $0.35-0.81$ & 0.003 \\
\hline Mucinous adenocarcinoma & & 0.60 & $0.40-0.90$ & 0.01 \\
\hline Signet-ring cell carcinoma & & 0.99 & $0.65-1.53$ & 0.98 \\
\hline
\end{tabular}

Abbreviation: TNM tumor-node-metastasis, CEA carcinoembryonic antigen, CRM circumferential resection margin

Our conclusions about the clinicopathologic relevance of MAC and SRCC were mainly in consistency with previous reports. They were associated with poorer tumor grade $[19,28-30]$, deeper primary tumor invasion $[19,22$, 28], regional lymph nodes metastasis [19, 28], more advanced TNM stage [29, 30], and higher level of CEA [22]. Both MAC and SRCC have been repeatedly reported to be less common in the rectum $[19,22,29,30]$. MAC was found more frequently in females [30]. We also demonstrated the relevance of MAC and SRCC with several postoperative features, including CRM, perineural invasion and tumor deposits. These factors had been found to be associated with poor survival $[16,17,31]$. From the above, the prognostic value of histologic subtypes might be confounded by these prognostic factors. Interestingly, although MAC was significantly associated with aggressive tumor features and advanced tumor stage, its survival difference from CA was not independently significant according to multivariate analysis. The prognostic value of MAC has been controversial. Several studies reported $\mathrm{MAC}$ to be an independent negative prognostic factor [32, 33]. However, most of the other reports were in accordance with our conclusions [19, 22, 23]. MSI-H, more frequently found in MAC, was identified as a positive prognostic marker in CRC $[24,25]$. This might partially explain the discordance between the clinicopathologic and prognostic relevance of MAC.

The consistency of clinicopathologic and prognostic relevance of SRCC highlighted a potential distinct aggressive tumor biology mechanism. Previous studies speculated that SRCC might arise from different cell origins compared with CA [34]. This distinct aggressive histologic subtype might benefit from intensified systemic therapy [26] and closer follow-up. Most importantly, our study identified that AM had a poor prognosis relative to SRCC. This subtype has not been well documented in the literature of CRC. In lung cancer, AM exhibited a greater genetic heterogeneity of EGFR mutation and ALK rearrangement. Thus, both intrinsic vicious biology and high heterogeneity might contribute to the aggressiveness and refractory of AM. Immunohistochemistry might be helpful for identification of tumor components [35], which should be considered when selecting systemic chemotherapy regimens.

The main limitation of our study is that this is a retrospective analysis of patients using the SEER database. The majority of patients in the SEER database were defined as adenocarcinoma NOS and were not included in the analysis. This could possibly cause some biases. Thus the results need to be validated in a more precise database.

\section{Conclusions}

Our study not only confirmed the clinicopathologic and survival differences of CA with MAC and SRCC with a large-sized sample, but also identified another histologic subgroup with aggressive tumor features and poor prognosis. The relatively large study population and the data source of the SEER database made the conclusions quite credible. However, there was no available information on DFS and genetic alterations, lack of such information is a limitation of our study.

\section{Supplementary information}

Supplementary information accompanies this paper at https://doi.org/10. 1186/s12885-019-6245-5.

Additional file 1 : Table S1. The frequency distribution of ICD-O-3 codes and histologic types in colorectal adenocarcinoma.

Additional file 2: Figure S1. Comparisons of prognosis in histological subtypes stratified by TNM stage.

\section{Abbreviations}

AJCC: American Joint Committee on Cancer; ALK: Anaplastic lymphoma kinase; AM: Adenocarcinoma with mixed subtypes; CA: Classic 
adenocarcinoma; CEA: Carcinoembryonic antigen; CRC: Colorectal cancer; CRM: Circumferential resection margin; EGFR: Epidermal growth factor receptor; ICD-O-3: 3rd edition of the International Classification of Diseases for Oncology; MAC: Mucinous adenocarcinoma; MSI-H: High microsatellite instability; NCCN: National Comprehensive Cancer Network; SEER: Surveillance, Epidemiology and End Results; SRCC: Signet-ring cell carcinoma; TNM: Tumor-node-metastasis

\section{Acknowledgments}

The authors acknowledge the staff members of the National Cancer Institute and their colleagues across the United States and at Information Management Services, Inc. who have been involved with the SEER Program.

\section{Authors' contributions}

$\mathrm{AY}$ and $\mathrm{HS}$ contributed to the conception and design of the study and drafted the manuscript; XW, MM, and ZH contributed to data analysis and interpretation; $\mathrm{JH}, \mathrm{TL}, \mathrm{SL}$, and LZ participated in data collection and literature research. All authors read and approved the final manuscript.

\section{Funding}

Not applicable.

\section{Availability of data and materials}

The data were retrieved from publicly accessible database "Surveillance, Epidemiology, and End Results" (SEER), the website is "https://seer.cancer. gov/". The definite data used in this study is available from the corresponding author on reasonable request.

\section{Ethics approval and consent to participate}

This study was deemed exempt from institutional review board approval by Sun Yat-sen University Cancer Center and the informed consent was waived. This study was conducted in accordance with the ethical standards of the World Medical Association Declaration of Helsinki.

\section{Consent for publication}

Not applicable.

\section{Competing interests}

The authors declare that they have no competing interests.

\section{Author details}

${ }^{1}$ Department of Experimental Research, Sun Yat-sen University Cancer Center, State Key Laboratory of Oncology in South China, Collaborative Innovation Center for Cancer Medicine, Guangzhou 510060, China. ${ }^{2}$ Department of Medical Oncology, Sun Yat-sen University Cancer Center, State Key Laboratory of Oncology in South China, Collaborative Innovation Center for Cancer Medicine, Guangzhou 510060, China. ${ }^{3}$ Department of Clinical Laboratory, Sun Yat-sen University Cancer Center, State Key Laboratory of Oncology in South China, Collaborative Innovation Center for Cancer Medicine, Guangzhou 510060, China. ${ }^{4}$ Zhongshan School of Medicine, Sun Yat-sen University, Guangzhou 510008, China. ${ }^{5}$ Department of Gastric Surgery, Sun Yat-sen university Cancer center, State key Laboratory of Oncology in South China, Collaborative Innovation Center for Cancer Medicine, Guangzhou 510060, China. 'Department of Medical Oncology, Dana-Farber Cancer Institute, Boston, MA, USA. 'Department of Emergency, Foshan Traditional Chinese Medicine Chancheng High-tech Zone Hospital, 10 Chunyang Road, Foshan 52800, Guangdong Province, China. ${ }^{8}$ Department of Breast Oncology, Sun Yat-sen University Cancer Center, State Key Laboratory of Oncology in South China, Collaborative Innovation Center for Cancer Medicine, 651 Dong Feng Road East, Guangzhou 510060, Guangdong Province, China.

Received: 3 June 2019 Accepted: 3 October 2019

\section{Published online: 08 November 2019}

\section{References}

1. Bray F, Ferlay J, Soerjomataram I, Siegel RL, Torre LA, Jemal A. Global cancer statistics 2018: GLOBOCAN estimates of incidence and mortality worldwide for 36 cancers in 185 countries. CA Cancer J Clin. 2018;68(6):394-424.

2. Chen W, Zheng R, Baade PD, Zhang S, Zeng H, Bray F, Jemal A, Yu XQ, He J. Cancer statistics in China, 2015. CA Cancer J Clin. 2016;66(2):115-32.
3. Gill S, Loprinzi CL, Sargent DJ, Thome SD, Alberts SR, Haller DG, Benedetti J, Francini G, Shepherd LE, Francois SJ, et al. Pooled analysis of fluorouracilbased adjuvant therapy for stage II and III colon cancer: who benefits and by how much? J Clin Oncol. 2004;22(10):1797-806.

4. Andre T, Boni C, Mounedji-Boudiaf L, Navarro M, Tabernero J, Hickish T, Topham C, Zaninelli M, Clingan P, Bridgewater J, et al. Oxaliplatin, fluorouracil, and leucovorin as adjuvant treatment for colon cancer. N Engl J Med. 2004;350(23):2343-51.

5. Benson AR, Schrag D, Somerfield MR, Cohen AM, Figueredo AT, Flynn PJ, Krzyzanowska MK, Maroun J, McAllister P, Van Cutsem E, et al. American Society of Clinical Oncology recommendations on adjuvant chemotherapy for stage II colon cancer. J Clin Oncol. 2004;22(16):3408-19.

6. Figueredo A, Charette ML, Maroun J, Brouwers MC, Zuraw L. Adjuvant therapy for stage II colon cancer: a systematic review from the Cancer Care Ontario program in evidence-based care's gastrointestinal cancer disease site group. J Clin Oncol. 2004;22(16):3395-407.

7. Strickler JH, Hurwitz HI. Palliative treatment of metastatic colorectal cancer: what is the optimal approach? Curr Oncol Rep. 2014;16(1):363.

8. Xu RH, Shen L, Li J, Xu JM, Bi F, Ba Y, Bai L, Shu YQ, Liu TS, Li YH, et al. Expert consensus on maintenance treatment for metastatic colorectal cancer in China. Chin J Cancer. 2016:35:13.

9. Compton CC, Greene FL. The staging of colorectal cancer: 2004 and beyond. CA Cancer J Clin. 2004;54(6):295-308.

10. Yoshioka Y, Togashi Y, Chikugo T, Kogita A, Taguri M, Terashima M, Mizukami T, Hayashi H, Sakai K, de Velasco MA, et al. Clinicopathological and genetic differences between low-grade and high-grade colorectal mucinous adenocarcinomas. Cancer. 2015;121(24):4359-68.

11. Cho YB, Chun HK, Yun HR, Kim HC, Yun SH, Lee WY. Histological grade predicts survival time associated with recurrence after resection for colorectal cancer. Hepatogastroenterology. 2009;56(94-95):1335-40.

12. Derwinger K, Kodeda K, Bexe-Lindskog E, Taflin H. Tumour differentiation grade is associated with TNM staging and the risk of node metastasis in colorectal cancer. Acta Oncol. 2010;49(1):57-62.

13. Ueno $H$, Mochizuki $H$, Hashiguchi $Y$, Ishiguro M, Kajiwara $Y$, Sato $T$, Shimazaki H, Hase K, Talbot IC. Histological grading of colorectal cancer: a simple and objective method. Ann Surg. 2008;247(5):811-8.

14. Douillard JY, Oliner KS, Siena S, Tabernero J, Burkes R, Barugel M, Humblet Y, Bodoky G, Cunningham D, Jassem J, et al. Panitumumab-FOLFOX4 treatment and RAS mutations in colorectal cancer. N Engl J Med. 2013; 369(11):1023-34.

15. Hemminki A, Mecklin JP, Jarvinen $H$, Aaltonen LA, Joensuu $H$. Microsatellite instability is a favorable prognostic indicator in patients with colorectal cancer receiving chemotherapy. Gastroenterology. 2000;119(4):921-8.

16. Jin M, Roth R, Rock JB, Washington MK, Lehman A, Frankel WL. The impact of tumor deposits on colonic adenocarcinoma AJCC TNM staging and outcome. Am J Surg Pathol. 2015;39(1):109-15.

17. Knijn N, Mogk SC, Teerenstra S, Simmer F, Nagtegaal ID. Perineural invasion is a strong prognostic factor in colorectal Cancer: a systematic review. Am J Surg Pathol. 2016;40(1):103-12.

18. Ren JQ, Liu JW, Chen ZT, Liu SJ, Huang SJ, Huang Y, Hong JS. Prognostic value of the lymph node ratio in stage III colorectal cancer. Chin J Cancer. 2012;31(5):241-7.

19. Nitsche U, Zimmermann A, Spath C, Muller T, Maak M, Schuster T, SlottaHuspenina J, Kaser SA, Michalski CW, Janssen KP, et al. Mucinous and signetring cell colorectal cancers differ from classical adenocarcinomas in tumor biology and prognosis. Ann Surg. 2013;258(5):775-82 782-783.

20. Okuno M, Ikehara T, Nagayama M, Kato Y, Yui S, Umeyama K. Mucinous colorectal carcinoma: clinical pathology and prognosis. Am Surg. 1988; 54(11):681-5.

21. Halvorsen TB, Seim E. Influence of mucinous components on survival in colorectal adenocarcinomas: a multivariate analysis. J Clin Pathol. 1988; 41(10):1068-72.

22. Park JS, Huh JW, Park YA, Cho YB, Yun SH, Kim HC, Lee WY, Chun HK. Prognostic comparison between mucinous and nonmucinous adenocarcinoma in colorectal cancer. Medicine (Baltimore). 2015;94(15):e658.

23. Inamura K, Yamauchi M, Nishihara R, Kim SA, Mima K, Sukawa Y, Li T, Yasunari M, Zhang X, Wu K, et al. Prognostic significance and molecular features of signet-ring cell and mucinous components in colorectal carcinoma. Ann Surg Oncol. 2015;22(4):1226-35.

24. Tanaka H, Deng G, Matsuzaki K, Kakar S, Kim GE, Miura S, Sleisenger MH, Kim YS. BRAF mutation, CPG island methylator phenotype and microsatellite 
instability occur more frequently and concordantly in mucinous than nonmucinous colorectal cancer. Int J Cancer. 2006;1 18(11):2765-71.

25. Andrici J, Farzin M, Sioson L, Clarkson A, Watson N, Toon CW, Gill AJ. Mismatch repair deficiency as a prognostic factor in mucinous colorectal cancer. Mod Pathol. 2016;29(3):266-74.

26. Hugen $\mathrm{N}$, Verhoeven RH, Lemmens VE, van Aart CJ, Elferink MA, Radema SA Nagtegaal ID, de Wilt JH. Colorectal signet-ring cell carcinoma: benefit from adjuvant chemotherapy but a poor prognostic factor. Int J Cancer. 2015; 136(2):333-9.

27. Sung CO, Seo JW, Kim KM, Do IG, Kim SW, Park CK. Clinical significance of signet-ring cells in colorectal mucinous adenocarcinoma. Mod Pathol. 2008; 21(12):1533-41.

28. Chew MH, Yeo SA, Ng ZP, Lim KH, Koh PK, Ng KH, Eu KW. Critical analysis of mucin and signet ring cell as prognostic factors in an Asian population of 2,764 sporadic colorectal cancers. Int J Color Dis. 2010;25(10):1221-9.

29. Hyngstrom JR, Hu CY, Xing Y, You YN, Feig BW, Skibber JM, Rodriguez-Bigas MA, Cormier JN, Chang GJ. Clinicopathology and outcomes for mucinous and signet ring colorectal adenocarcinoma: analysis from the national Cancer data base. Ann Surg Oncol. 2012;19(9):2814-21.

30. Kang H, O'Connell JB, Maggard MA, Sack J, Ko CY. A 10-year outcomes evaluation of mucinous and signet-ring cell carcinoma of the colon and rectum. Dis Colon Rectum. 2005:48(6):1161-8.

31. Machiels JP, Aydin S, Bonny MA, Hammouch F, Sempoux C. What is the best way to predict disease-free survival after preoperative radiochemotherapy for rectal cancer patients: tumor regression grading, nodal status, or circumferential resection margin invasion? J Clin Oncol. 2006;24(8):1319 1320-1321.

32. Verhulst J, Ferdinande L, Demetter P, Ceelen W. Mucinous subtype as prognostic factor in colorectal cancer: a systematic review and metaanalysis. J Clin Pathol. 2012;65(5):381-8.

33. Chen JX, Tang XD, Xiang DB, Dong XL, Peng FY, Sun GY. TNM stages and prognostic features of colorectal mucinous adenocarcinomas: a meta analysis. Asian Pac J Cancer Prev. 2012;13(7):3427-30.

34. Borger ME, Gosens MJ, Jeuken JW, van Kempen LC, van de Velde CJ, van Krieken JH, Nagtegaal ID. Signet ring cell differentiation in mucinous colorectal carcinoma. J Pathol. 2007;212(3):278-86.

35. Fujimoto Y, Togo S, Tulafu M, Shimizu K, Hayashi T, Uekusa T, Honma Y, Namba Y, Takamochi K, Oh S, et al. Variation in the expression levels of predictive chemotherapy biomarkers in histological subtypes of lung adenocarcinoma: an immunohistochemical study of tissue samples. Int J Clin Exp Pathol. 2015;8(9):10523-33.

\section{Publisher's Note}

Springer Nature remains neutral with regard to jurisdictional claims in published maps and institutional affiliations.

Ready to submit your research? Choose BMC and benefit from:

- fast, convenient online submission

- thorough peer review by experienced researchers in your field

- rapid publication on acceptance

- support for research data, including large and complex data types

- gold Open Access which fosters wider collaboration and increased citations

- maximum visibility for your research: over $100 \mathrm{M}$ website views per year

At $\mathrm{BMC}$, research is always in progress.

Learn more biomedcentral.com/submissions 